\title{
The Cultivation of Professional Ability for Fashion-Majors Based on Test of English Proficiency (Oral)
}

\author{
Weili Zi \\ Foreign Language Department, Beijing Institute of Fashion Technology, Beijing, China \\ Email: zwlpost@126.com
}

Received 11 April 2016; accepted 31 May 2016; published 3 June 2016

Copyright (C) 2016 by author and Scientific Research Publishing Inc.

This work is licensed under the Creative Commons Attribution International License (CC BY).

http://creativecommons.org/licenses/by/4.0/

(c) (i) Open Access

\begin{abstract}
The new demand is put forward for the cultivation of fashion-major students because of the change of the development modes in textile industry. However, College English Teaching nowadays is still conducted with the CET4-oriented goal, which can't satisfy the demand of the companies or the enterprises for talented people with strong professional capability, especially in the textile industry. In view of inconsistency between poor professional ability of fashion-major students and social standard for talents, the reform based on ability-oriented TEP (oral) is conducted. This paper aims to reflect on the cultivation of fashion-major students based on the curriculum reform centered on TEP (oral), suggesting that it is the best way to integrate the cultivation of professional abilities into the college English teaching process and practice process along with some effective and constructive suggestions.
\end{abstract}

Keywords

TEP (Oral), Fashion-Major Students, Professional Ability

\section{Introduction}

The major teaching task of the fashion institutes is to cultivate the application-oriented and innovative talents over the need of regional economical development and social development to meet the needs of constructing fashion and cultural creative industry, city of design and fashion capital as well. While, according to the survey, most companies affix the value to the advanced talents with the international view and strong professional ability.

Professional ability covers two aspects in this paper. In terms of individual ability, it includes the ability to analyze and solve the problem, the ability of critical thinking, creative ability and the independent learning abil- 
ity. In terms of social ability of an individual, it includes working responsibility, cooperative ability, collaborative ability, effectively communicative ability and social conscience. While for the present College English teaching, the only goal is to help more students pass CET Band 4, with the focus on the learning result instead of the learning process, with the lack of the awareness of professional ability and even the ignorance, which obviously go against the standards of talents from the companies.

\section{Problems of College English Teaching in Beijing Institute of Fashion Technology}

\subsection{College English Teaching Problems in BIFT}

College English Test Band 4 (CET-4), started officially in 1987, is the national teaching test presided by higher education department in the ministry of education for the under-graduated and postgraduates, completing college English band 4 required by education outline. The test involves four basic skills, including listening, reading, writing and translation. Fashion-major students often participate in fashion show, international conference and attend many lectures concerning fashion design, while their application abilities are not quite satisfactory, such as they can't give perfect and standard presentation, they often fail to communicate with the foreign designer successfully, they can't effectively convey the national costume culture to the foreigners, and etc. Besides, to most fashion-major students, the problem is they are found to perform poorly in solving and analyzing problems, working collaboratively, and lack oral skills, critical thinking, responsibility and even creative awareness, although they get higher scores in CET-4. Even there is an unbalanced phenomenon: the higher the score of CET-4, the poorer professional ability, which urges us to put more weight on cultivation of professional ability for those students in English teaching process.

\subsection{Correlation Analysis between TEP (Oral) and CET-4}

\subsubsection{Participants}

The freshmen of 2014 grade are required to take the College English Placement Test (CEPT) in BIFT, Fashion-majors cover two specialties which are fashion design and fashion engineer. All are classified into two levels: Level A and Level B according to students' performance of CEPT and their English National College Entrance Examination (NCEE). Students are from all over the country. Level A is the advanced class with the score of NCEE ranging from 120 to 145 and average performance of the CEPT and NCEE ranging from 90 to 115. So, they are considered at the similar level of English with Fashion design A as the experimental class and Fashion engineer A as the controlled class. Level B is the medium class with the score of NCEE ranging from 90 to 119 and average performance of the CEPT and NCEE ranging from 60 to 89. Fashion design B is taken as the experimental class while fashion engineer B as the controlled class. There are 115 students in the experimental class while 120 students in the controlled. Some students failed to pass level C and level B, so, only 144 students participated Level A test.

\subsubsection{Correlation Analysis}

After one and half year experiment, students of grade 2014 have participated in the three level tests (A-level, B-level and C-level) of TEP (oral), they also participated in the CET-4. We analyzed the two examinations, hoping to find out the correlation between TEP (oral) and CET-4.

(Note: both experimental groups and controlled groups with their three-level oral scores are analyzed in terms of listening scores and overall scores of CET-4).

As is shown in Table 1, Except the low correlation of B-level scores in TEP (oral) with their listening scores and overall scores in CET-4, There is no correlation between A-level and C-level scores in TEP (oral) and listening and overall scores in CET-4, the result of which is consistent with that of Professor Xihua Zhang from Beijing Second Foreign Language Institute. According to her research result, there is a weak correlation between CET-4 scores and oral ability (Zhang, 2014), this result shows that CET-4-oriented teaching excessively focuses on learning result and examination, ignoring the application ability, while application-oriented teaching attaches importance to the practical abilities, emphasizing professional ability.

In view of this, we participated in TEP (oral) project launched by Beijing municipal education commission. A three-academic year experiment is conducted in our institute based on TEP (oral). We think that the present teaching mode and curriculum design require improvement, and that the cultivation of professional ability for 
Table 1. Correlation analysis between CET-4 scores and TEP (oral) scores (A-level, B-level and C-level).

\begin{tabular}{cccccccc}
\hline & $\begin{array}{c}\text { Experimental group } \\
\text { CET-4 (overall) }\end{array}$ & $\begin{array}{c}\text { Controlled groups } \\
\text { CET-4 (overall) }\end{array}$ & $\begin{array}{c}\text { Experimental group } \\
\text { CET-4 (listening) }\end{array}$ & $\begin{array}{c}\text { Controlled groups } \\
\text { CET-4 (listening) }\end{array}$ \\
\hline $\begin{array}{c}\text { Experimental group C-level } \\
\quad 1\end{array}$ & 0.177 & 1 & 0.024 & 1 & 0.299 & 1 & 0.548 \\
$\begin{array}{c}\text { Pearson correlation } \\
\text { Significant (double side) }\end{array}$ & 0.399 & & 0.938 & 0.177 & 0.065 \\
$\begin{array}{c}\text { Experimental group B-level } \\
\quad 1\end{array}$ & $0.449^{*}$ & 1 & 0.172 & 1 & $0.430^{*}$ & 1 & 0.351 \\
$\begin{array}{c}\text { Pearson correlation } \\
\text { Significant (double side) }\end{array}$ & & 0.024 & & 0.573 & & 0.032 & 0.239 \\
$\begin{array}{c}\text { Experimental group A-level } \\
\quad 1\end{array}$ & -0.324 & 1 & -0.175 & 1 & 0.388 & -0.124 \\
$\quad \begin{array}{c}\text { Pearson correlation } \\
\text { Significant (double side) }\end{array}$ & 0.163 & & 0.587 & & 0.074 & 0.700 \\
\hline
\end{tabular}

Note: *Significant correlation on 0.05 (double side).

students are supposed to be integrated into college English teaching process.

\section{Research Background}

\subsection{TEP (Oral)}

TEP (Oral), short for Test of English Proficiency Oral, is a College English teaching reform project carried out by Beijing Municipal Education Commission mainly in municipal colleges and universities. It is intended to cultivate the internationalized talents and the application-oriented graduates of the international metropolis. The implementation of this project can provide the municipal colleges and universities with the theoretical and practical guidance with the demonstration effect for other universities. TEP (oral) mainly examine the application abilities, as is shown in Table 2.

\subsection{Introduction of the Experiment Based on TEP (Oral)}

During September, 2014 and January, 2016, the three-academic year course reform is conducted by determining the experimental group and the controlled group from fashion-major classes of grade 2014. Both groups have taken the three-level oral examinations. We record the whole process of experiment with the reflection on the result.

\subsection{Curriculum Reform Based on TEP (Oral)}

Curriculum reform is centered on professional ability of fashion-major students, in which knowledge teaching is combined with developing students' application abilities, including problem-solving ability, critical thinking ability, creative ability, learning ability, collaborative ability and the sense of responsibility. Integrating the elements of professional ability into college English teaching process is the major teaching reform based on TEP (oral).

\subsubsection{English In-Class and Out-Class Teaching Mode}

The curriculum is adjusted based on teaching goal. The intensive reading for the experimental group is reduced to 2 hours each week, while listening and speaking class is added to 2 hours each week; the controlled group still follows the traditional pattern with 3-hour intensive reading and 1-hour listening. Teaching materials are also different. The experimental group adopts TEP (Oral) book besides New Horizontal Concept English series, while the controlled group only use the latter.

1) Flipped Classroom

In in-class teaching process, we focus on students' ability to put forward questions, to analyze questions and to solve the problems involved with learner-centered learning pattern under the guidance of teachers. Students play the principal part of information processing in learning, and they are the active constructors of learning, 
Table 2. Form and content of TEP (oral) (Zhang, 2014).

\begin{tabular}{|c|c|c|c|}
\hline level & C-level (Primary) & B-level (Medium) & A-level (Advanced) \\
\hline Time & 10 minutes & 12 minutes & 15 minutes \\
\hline 1 & daily conversation (1 minute) & daily conversation (1 minute) & daily conversation (1 minute) \\
\hline 2 & $\begin{array}{l}\text { Picture description Summary } \\
\text { (4 minutes) }\end{array}$ & $\begin{array}{l}\text { Passage retelling mutual questions and answers } \\
\text { based on the retelling ( } 6 \text { minutes) }\end{array}$ & $\begin{array}{l}\text { Summary and evaluation } \\
\text { (9 minutes) }\end{array}$ \\
\hline 3 & $\begin{array}{l}\text { Presentation based on the topic } \\
\text { ( } 5 \text { minutes) }\end{array}$ & Topic discussion (5 minutes) & $\begin{array}{l}\text { Topic discussion and debate } \\
\text { (5 minutes) }\end{array}$ \\
\hline
\end{tabular}

while teachers are the mentors or facilitators who help and promote the construction of the knowledge, who encourage students to play the active role in teaching and learning process. Students are required to learn and discuss the new knowledge collaboratively for information transfer out of class, while, in class, teachers would help solve the problems, enlarge the knowledge, widen their view, and lead them to the absorption and internalization by observing, analyzing, generating what they have discussed. For example, students are required to know the theme of a video clip over a certain subject, put forward the related questions, and give the critical discussion about the content or the comment on the theme. Each student should be involved in discussion and generalization, the result of which is reported to the leader. These works are completed out of class. Then, the group leader would give the presentation in class based on the group discussion, at the same time; other members can complement what the leader has missed. Finally, the interaction of teachers with students, or students with students are achieved through in-depth explanation and guidance from teachers. As is said, "Internet offers the new learning environment to English teaching while bringing about emotional deficiency. Emotional communication between teachers and students is the key to successful in-class teaching” (Ma \& Jiang, 2013). So, emotional interaction in flipped class promotes learning.

2) Out-class Collaborative Learning under the Network Environment

Throughout the domestic and foreign researches on cooperative learning, in-class collaborative learning is more valued than the out-class collaboration (Xu, 2013). In recent years, many experts point out that the researchers are supposed to extend their attention to the out-class study (Benson, 2007). Learning is the knowledge-constructing process for students to construct their knowledge actively. In this process, students can acquire the knowledge, develop the communicative ability and foster the spirit of teamwork. For example, a four or five-member group is required to act as English commentators in National Costume Museum of BIFT, which is a good practice for the profession-ability cultivation. They need to collect information concerning costume or fashion, on one hand, and have a good knowledge of the Costume Museum. On the other hand, they have to train the communicative skills consistently with the awareness of the fact that the interpretation itself and the interpretation ability are equally important. So, this is really a challenge to them. As we all know knowledge comes from the interaction of the students and the environment, and they explore the doubt, give full play to creation and develop the well-disciplined attitude. Out-class learning doesn't mean studying lonely, but characterized by the remarkable society which covers communication, consultation and cooperation (Littlewood, 1996). Online discussion for problem-solving, offline collaborative practice make them truly immersed in the reality, where their enthusiasm and initiative for learning is fully mobilized. The right to decide the knowledge construction and creation make students more interested in involving themselves in learning activity in a collaborative learning environment.

\subsubsection{Course Evaluation}

Some institutes in China put forward the teaching goals which go against the practical needs of teaching, and fail to satisfy students' needs; and some even pay inadequate attention to the formative assessment, they can't provide individualized feedback. Therefore, College English is required to adopt the varied and comprehensive evaluations to match the teaching goal and teaching needs (Jin, 2015).

1) Oral Test

Promoting learning and teaching through exams is a major educational function. Students' speaking ability is enforced by TEP (oral), monthly oral quiz and weekly presentation concerning costume culture, which do draw the attention of students to the importance of oral expression which are weakness for them. Over one and half year, their awareness of improving oral ability is enhanced through various class activities, including the differ- 
ent oral test for many times each term, 5-minute information report before class, recitation of what have been learnt, presentation and debate based on the certain topic in class, oral summary and reflection at the end of class, which help improve their expressive ability and critical thinking ability.

2) Diversified Assessment

It is quite necessary to record all the activities concerning oral practices for each student, especially, tracking dynamically their oral ability changes. Preparing a profile for each student, recording their performance of pre-experiment, experiment and post-experiment, would be helpful for both individualized guidance and motivation to learn actively. Besides, our assessment also involves participation in English Corner, practice of acting as commentators or interpreters for foreigners, participating in Debate Competition, Oral English Contest, Movie Dubbing Competition and dramatic performance and the like. The assessment of contribution in collaborative activities, assignments and the like is completed through students' mutual evaluation under teachers' supervision. Peer assessment is quite important in that the quick response ability, strong sense of responsibility and critical thinking are definitely necessary on grounds of the principle "fairness".

\subsubsection{The Second Classroom Teaching Reform}

The second classroom teaching, as an important auxiliary teaching part, plays an active role in improving students' professional ability. Omni-En is one of the distinguishing features in BIFT. In-class time is limited, so the second class becomes increasing important, especially for language teaching.

In view of the important role that the second class plays, action research of constructing the second class is conducted in 2014. The amazing thing is that the action research is conducted by students through two cycle stages under teachers' supervision, including the first stage-interview for the attitudes towards the corner, finding problems, putting forward hypothesis, determining plan, carrying out plan, and the second stage-reflecting based on the first stage, finding the new problems, determining the corresponding plan, carrying out the plan and reflect again for final summary.

Omni-En creates a good language communication environment, where students' communicative ability is fully developed, most importantly, their professional ability is boosted a lot. During operation, we encountered numerous problems, including the conflict of Corner activity and the business of cafe, the less participants, failure to effectively communicate with each other, low enthusiasm, the offense between students and the foreign teachers because of different backgrounds and so on. All those problems are finally solved by themselves.

Faced with these problems, the organizers of students' activities and the participants are supposed to have the professional ability, including analytical ability, problem-solving ability, critical thinking ability, even creative ability. Besides, the sense of responsibility, collaborative ability, expressive ability is also indispensable. After two terms, they say they have "reaped the reward"-this place has been a home, where students would come for the help when facing troubles, or when coming up with a new designing idea for share; besides, some constant participants earn the prize in oral contest, and some have performed quite well in IELTS, and get the offers from universities abroad.

\subsubsection{Course Construction}

1) Reform of Course Content and Form

A series of teaching syllabus and examination syllabus are set based on college English teaching goal and the need of students' future employment, excellent teaching materials are determined, the application abilityoriented quality curriculum and teaching team are constructed, which are supposed to be the significant measures to guarantee the successful implement of course reform and teaching quality. In class teaching, studentscentered teaching and application-oriented goal can promote students' enthusiasm, motivation and creativity. Students are taught in accordance of their aptitude, combining professional knowledge with language teaching, which is so-called content-based instruction (CBI), to further optimize in-class teaching. This practice, on one hand, improves students' subject knowledge and cognitive ability, on the other hand, students' language competence is enhanced (Zi, 2013). CBI refers to a teaching mode implemented by integrating the language teaching and the content with the teaching focus shifted from learning language itself to language learning through disciplinary knowledge learning (Brinton et al., 1989; Krueger \& Ryan, 1993). Yang \& Zhao (2011) conducted an empirical study of the effect of content-based instruction on the English majors' critical thinking skills, and the study has confirmed that CBI can facilitate the advancement of English majors' thinking skills. Besides, computer-assisted classroom teaching mode is also adopted with the emphasis of classroom interaction and role of 
modern teaching technology and mediums in cultivating students’ professional ability.

2) Reform of Course Assessment

A set of scientific and operable examination system has been established. As we all know, the traditional teaching assessment in China tends to pay more attention to language itself, the learning result and the comprehensive, while overlooking the ability, the learning process and the individual, which fail to meet the severe challenges of internationalization of higher education (Cai, 2013). Our course assessment covers the formative assessment and summative assessment. Establishing multiple formative assessment model based on network platform can supervise and instruct students effectively. Emphasizing the process of language teaching to promote learning through examination and evaluation would optimize the curriculum evaluation system for the purpose of improving the quality of teaching, cultivating qualified talents for social development.

Above all, course reform or teaching mode all focus on the profession ability, including analytical ability, problem-solving questions, critical thinking ability, creativity, autonomous study, collaborative ability and sense of responsibility, while various teaching modes are adopted, such as cooperation, exploration, assignment, presentation, discussion, even argumentation. Professional abilities are integrated into each process of in-class and practical teaching. And students' ability is greatly improved.

\subsection{Result}

On the $29^{\text {th }}$, Oct. 2015, A-level TEP (oral) are held with 144 participants, 6 examination rooms and 12 examiners who have received the standard training from Beijing Municipal Education Commission. After test, the correlation of grading between chief examiners and the assistant examiners in each examination room is analyzed in order to guarantee the objectivity of grading. The statistical result shows the correlation of grading between chief examiners and the assistant examiners in the six rooms is respectively as the follows: Room $1=0.753^{* *}$, Room $2=0.587^{* *}$, Room $3=0.941^{* *}$, Room $4=0.890^{* *}$, Room $5=0.928^{* *}$, Room $6=0.707^{* *}$. This shows the high credibility in grading.

As is seen in Table 3, students in the experimental class has got the excellent achievement in A-level, the advanced level of TEP (oral), which proves that the students in application ability-oriented class teaching do perform better than those following the exam-oriented teaching outline. Besides, in March, 2016 IFFTI international conference hosted in BIFT, most volunteers are from the experimental class, and they are praised for their communication and response skills, their ability to solve the problems, their responsibility, commitment, and interpreting ability at the end of the conference by the foreign designers, experts and teachers from fashion colleges all over the world.

\section{Discussion and Reflection}

College English reform based on TEP (oral) arouses our concern about the cultivation of fashion-major students in terms of professional abilities, which also provokes our thinking of the relationship between course reform, teachers' professional ability and cultivation of students' professional ability in the following.

\subsection{Course Reform Plays an Important Role in Cultivation of Students' Professional Ability}

Improving students' professional ability and enhancing their creative ability are indispensable to course reform adapting to the need of national development. The more adaptable to the social needs in course reform, the more talents with strong professional ability. Practical teaching reform plays an important part in the reform, because the real professional skills can be attained in the practical activities. Of course, the evaluation that matches course reform should center on the professional ability, including analytical ability, problem-tackling ability,

Table 3. Result of TEP (oral) A-level between the experimental class and the controlled class.

\begin{tabular}{lcccc} 
& Number of people & Major & The passing number & The passing rate \\
\hline The experimental class & 67 & Fashion design \& Fashion engineer & 62 \\
The controlled class & 77 & Fashion design \& Fashion engineer & $63 \%$ \\
\hline
\end{tabular}

$\overline{\text { Note: }{ }^{* *} \text { Meaning significant correlation at } 0.01 \text { level. }}$ 
critical thinking, creative ability, autonomous learning ability, collaborative ability and sense of responsibility.

\subsection{Teachers' Professional Ability Plays an Important Role in Cultivation of Students' Professional Ability}

Teachers' professional ability covers "the ability to understand other people, the ability to interact with others, the ability to conduct management, and the ability to do educational research", which are quite significant in effectively imparting the knowledge and cultivating people. Without those quality abilities, it is impossible to cultivate the desired talents with strong professional abilities.

In China, professional education has developed from the previous scale expansion into a new stage of improving education quality. And teachers' professional ability has the decisive influence on accomplishing this task, so it is the same case for the course reform based on TEP (oral) in BIFT. Teachers' professional abilities, behavior and attitudes are crucial for the development of students' professional abilities (Zhang \& Zhao, 2015). Therefore, the improvement of teachers' professional ability can assure them of effectively organizing teaching, flexibly combining the cultivation of profession ability with class teaching, to achieve the desired goal.

Above all, the TEP (oral) as an English teaching test triggers professional ability-oriented reform of College English teaching in BIFT, which is also the aim to carry out the project. As what professor, Xihua Zhang, stresses the final goal that TEP (oral) is going to achieve, encourage the educational reform and improve students' application ability. The committee member from Beijing Municipal Education Committee, Kan Huang emphasizes in a conference, by carrying out TEP(oral), on one hand, a new idea of teaching and learning is conveyed to students; on the other hand, students are required to improve their language application ability, and cultivate the professional consciousness to strengthen their professional abilities, so that they can work hard to live up to the standard of international talents, which is the ultimate goal for our College English reform.

\section{Acknowledgements}

The paper is under both the project of Reform and Innovation Team of College English Teaching in BIFT (JGTD-1406) and the project of Research on College English Teaching Mode Based on Microlectures (JG1521).

\section{References}

Benson, P. (2007). Autonomy in Language Teaching and Learning. Language Teaching, 40, 21-40. http://dx.doi.org/10.1017/S0261444806003958

Brinton, D., Snow, M., \& Wesche, M. (1989). Content-Based Second Language Instruction. Boston: Heinle \& Heinle Publisher.

Cai, J. G. (2013). Adjustment of Educational Assessment of EFL at Tertiary Level against the Background of Internationalization of Higher Education. Computer-Assisted Foreign Language Education in China, 1, 3-8.

Jin, Y. (2015). Constructing a Comprehensive and Diversified College English Curriculum Evaluation System: Needs Analysis and the Way Forward. Foreign Language in China, 12, 5.

Krueger, M., \& Ryan, F. (1993). Language and Content: Discipline and Content-Based Approaches to Language Study. Lexington: DC Heath.

Littlewood, W. (1996). Autonomy: An Anatomy and a Framework. System, 24, 427-435. http://dx.doi.org/10.1016/s0346-251x(96)00039-5

Ma, W. L., \& Jiang, Y. (2013). A Research into the Problems and Their Causes of Non-Language Major Tertiary-Level Students’ English Listening in Blended Teaching Model. Foreign Language and Literature (Bimonthly), 1, 143.

Xu, J. F. (2013). An Empirical Study of the Effect of Out-Class Collaborative Study on College Students' English Autonomous Learning Ability. Journal of PLA University of Foreign Languages, 5, 39.

Yang, D. X., \& Zhao, Y. P. (2011). The Effect of Content-Based Instruction on English Majors' Critical Thinking Skills. Foreign Language Education, 32, 61-64.

Zhang, X. H. (2014). The Study of Test of English Proficiency Oral for Non-English Majors. Journal of Beijing Second Foreign Languages Institute, 8, 72.

Zhang, Z. X., \& Zhao, Z. Q. (2015). The Present Status and Prospect of Professional Ability in Vocational Education. Chi- 
nese Vocational and Technical Education, 12, 63-67.

Zi, W. L. (2013). Application of Presentation Teaching Mode in Undergraduate College English Teaching of Non-English Major. China Higher Education Research, 7, 108-110. 